\title{
Computed tomographic imaging of the airways: relationship to structure and
} function

\author{
P.A. de Jong**,ף, N.L. Müller", P.D. Paré ${ }^{*}$ and H.O. Coxson $\#,{ }^{\star}$
}

\begin{abstract}
Alterations in the structure of the airways, collectively termed airway remodelling, contribute to airflow obstruction in a variety of chronic lung diseases. While histology has provided valuable insights into the structure of airway wall remodelling, this technique is invasive and does not allow the longitudinal analysis of airway wall dimensions. Technical advances in computed tomography allow the assessment of airway wall dimensions, and are ideally suited for the noninvasive investigation of the pathogenesis of airway wall remodelling and the evaluation of new therapeutic interventions. The aim of this article is to review the use of computed tomography in the investigation of airway structure and function in health and disease.
\end{abstract}

KEYWORDS: Airways, asthma, chronic obstructive pulmonary disease, computed tomography, cystic fibrosis, lung structure and function

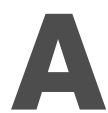

lterations in the structure of the airways, collectively termed airway remodelling, contribute to airflow obstruction in a variety of lung diseases including: asthma, chronic obstructive pulmonary disease (COPD), and cystic fibrosis (CF). Airway remodelling is defined as changes in the composition, content and organisation of the cellular and molecular constituents of the airway wall; these changes can contribute directly to airway narrowing and/or exaggerate the effect of airway smooth muscle contraction. The detection and quantification of airway remodelling have been based on the use of histological examination. Such studies have provided valuable information on the processes and consequences of airway remodelling, but require access to surgical or autopsy samples of the airways and are necessarily cross-sectional in design. Noninvasive methods are required to further investigate the pathogenesis of airway wall remodelling, to assess changes over time, and to allow the assessment of new therapeutic interventions designed to attenuate or reverse these structural changes. Technical advances in computed tomography (CT) allow an assessment of airway wall thickness and cross-sectional area in vivo that is comparable to histological examination (fig. 1). However, the information that can be obtained from $\mathrm{CT}$ is essentially less detailed than that obtained on histological examination. For example, CT cannot distinguish which components of the airway wall are thickened. Despite this limitation, the ability to measure multiple airways relatively, noninvasively and repeatedly offers major potential advantages. The aim of the current article is to review the use of $\mathrm{CT}$ in the investigation of airway structure and function in health and disease. Although both qualitative and quantitative studies are reviewed, the quantitative studies are emphasised because of their inherent advantages and because they directly reflect the digital data on which this imaging modality is based.

\section{GENERAL METHODS}

The original CT scans designed to assess airway $2 \mathrm{~mm}$ axial), which were acquired using a "stop and shoot" protocol and were reconstructed using an edge-enhancing algorithm, known as the high-resolution CT (HRCT) protocol. Usually, there was a gap of $\geqslant 10 \mathrm{~mm}$ between the images because of radiation concerns and the limitations in obtaining truly sequential images using the axial technique. Most of the published analysis techniques have been developed and validated using these acquisition paradigms, unless breathhold time and radiation exposure were not a concern, such as in the study of phantoms or animals. Even the advent of spiral CT scanners, structure involved thin-slice images (typically 1-

\section{AFFILIATIONS}

*Dept of Paediatric Pulmonology, Erasmus MC-Sophia, Rotterdam, The Netherlands.

\# James Hogg iCAPTURE Centre for Cardiovascular and Pulmonary Research, St Paul's Hospital, and "Dept of Radiology, Vancouver General Hospital, University of British Columbia, Vancouver, $\mathrm{BC}$, Canada.

\section{CORRESPONDENCE}

H.O. Coxson

Dept of Radiology

Vancouver General Hospita

855 West 12th Avenue

Room 3350 JPN

Vancouver

$\mathrm{BC}$

V5Z 1M9

Canada

Fax: 16048754319

E-mail: harvey.coxson@vch.ca

Received:

January 192005

Accepted after revision:

March 252005

European Respiratory Journal Print ISSN 0903-1936

Online ISSN 1399-3003 


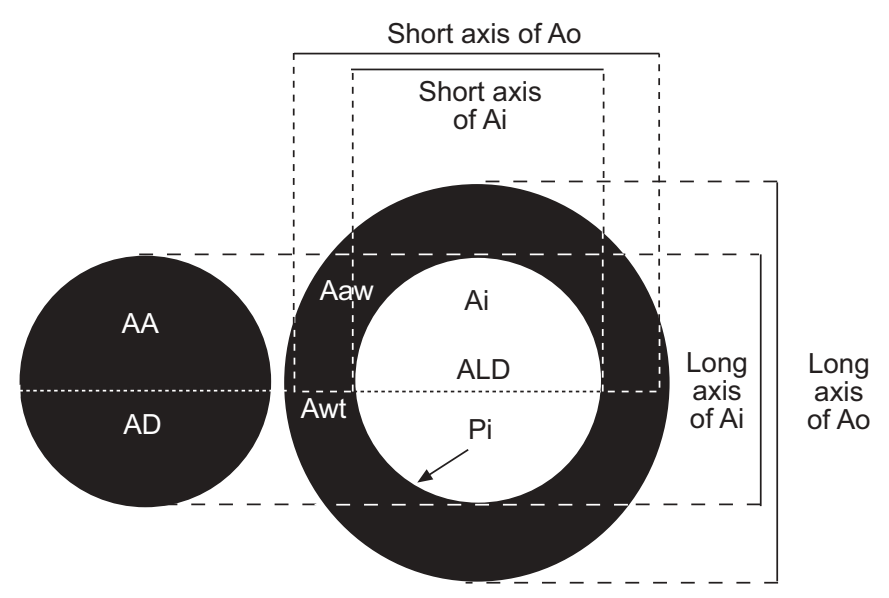

FIGURE 1. Computed tomography (CT)-estimated dimensions of the airway lumen and wall, and accompanying pulmonary artery. This schematic shows the various measurements that can be made on CT images of airways and the vessels, which frequently accompany them. Linear measurements include: the airway perimeter $(\mathrm{Pi})$; the long and short axes of the outer airway area $(\mathrm{Ao})$ and the lumen area (Ai); wall thickness (Awt); airway lumen diameter (ALD); airway outer diameter $(A o D=A L D+A w t)$; and arterial diameter (AD). Ratios of various linear dimensions include: ALD/AD; Awt/AD; Awt/ALD; as well as long to short axis ratios, which are a measure of the obliquity of the section. The area dimensions include: Ai; airway wall area (Aaw); outer airway area $(\mathrm{A} O=\mathrm{Aaw}+\mathrm{Ai})$; and arterial area $(\mathrm{AA})$. Ratios of various areas include: Ai/AA; Aaw/AA; and percentage wall area (WA\%=Aaw/Ao $\times 100 \%)$. The square root of Aaw is often derived, since it is relatively linearly related to $\mathrm{Pi}$ Finally, airway dimensions can be referenced to body surface area (e.g. Aaw/BSA and Awt/BSA).

where the images can be acquired while the table continuously moves, did not change this approach significantly. However, the introduction and proliferation of multidetector-row CT (MDCT) scanners have completely changed the approach to $\mathrm{CT}$ image acquisition. It is now possible to acquire thin-slice images of the whole chest, often referred to as volumetric imaging, with $0.5-1-\mathrm{mm}$ thick slices during a single breathhold. Furthermore, these scanners produce true isotropic voxels, allowing image reconstructions in which the $Z$ dimension (slice thickness) is the same dimension as the $X$ and $\mathrm{Y}$ (in plane) resolution. The isotropic voxels make it possible to measure airways in true cross-section at any location, using retrospective reconstruction of the images to achieve a cross-sectional image of the airway. A number of complex algorithms have been developed that allow this angle correction and measurement of the wall and lumen [1-4]. Therefore, studies can be tailored to the clinical or research question being asked in order to maximise image quality whilst minimising the radiation dose. Volumetric CT also allows the generation of maximal intensity projection and minimal intensity projection (MIN-IPS) images, and MIN-IPS images have been shown to be particularly helpful in the detection of subtle emphysema [5].

Images acquired for analysis of airways are usually obtained during suspended inspiration. Some investigators have proposed the use of spirometric gating, since airways dilate with increases in lung volume; the lumen area and the ratio of wall area to lumen area vary as a function of lung volume. Furthermore, the goal of imaging studies is often the comparison of airway dimensions (between individuals or within an individual over time), so it is important to compare images of the same airway at the same or closely comparable lung volume. Studies in experimental animals [6] have shown that airways are completely dilated at transpulmonary pressures $>10 \mathrm{cmH}_{2} \mathrm{O}$, and suggest that, if reasonable inspiratory efforts are made, it may be legitimate to compare airways over time without the need for spirometric gating. Conversely, the area-pressure curve of diseased airways is likely to be abnormal. If these airways are less compliant than normal, the lung volume and transpulmonary pressure at which the scan is performed could have a more important effect on airway dimensions.

CT scans of children and infants who cannot voluntarily hold their breath present a significant problem for airway analysis. Infants aged $<4$ yrs are usually sedated and scanned during quiet breathing; the resultant images have substantial motion artefact and are generally not suitable for the assessment of airway structure. To solve this problem, LONG and coworkers [7-9] developed, and employed, a CT technique called "volume-controlled $\mathrm{CT}^{\text {", }}$ to scan sedated infants at a standardised volume during apnoea. Infants are hyperventilated, and the hypocarbia and Herring-Breuer reflex accompanying chest wall expansion causes an apnoea that is prolonged enough to acquire the images.

Since most of the CT studies of airways were carried out before the introduction of MDCT scanners, and because many institutions do not have the ability to control for lung volume during CT scans, the theoretical advantages of increased precision offered by these techniques have not yet been demonstrated and require further study. Investigators have had to resort to other methods to match airways, such as in a recent study by NIIMI et al. [10] where a large central airway that could easily be identified and measured on serial CT studies was compared before and after an intervention.

\section{Quantitative assessment of larger airways}

In the initial studies in which airway dimensions were measured using CT, the investigators relied on manual tracing of the airway images [11-15]. These techniques are extremely time consuming and prone to error. Therefore, computer-aided and automated techniques have since been developed to measure airway lumen and wall dimensions. The first such method for measuring airway lumen used a Hounsfield unit (HU) threshold cut-off value. This technique involves identifying the airway, and measuring the x-ray attenuation values within the lumen. MCNITT-GRAY et al. [16] reported that the airway lumen area could be accurately measured by including all pixels beyond a threshold cut-off of $-500 \mathrm{HU}$, and KING et al. [17] reported that a threshold of -577 HU produced the least error. However, the most commonly reported method for measuring the airway lumen and wall areas relies on the "full-width-at-half-maximum" (or "half-max") technique. This method requires that a seed point be placed in the lumen and the $x$-ray attenuation values measured along rays cast from this point outward toward the airway wall in all directions. As a ray enters the wall, the attenuation will increase and then decrease as it passes into the lung parenchyma. The distance between the point at which the attenuation is halfway to the maximum on the lumen side and halfway to the local 
minimum on the parenchymal side is considered to be the wall thickness (fig. 2) [18, 19]. Although this method provides a standardised and unbiased measurement, it has limitations. When CT scan measurements using this method are compared with phantoms and anatomical specimens [19], the CT scans consistently overestimate airway wall area and underestimate lumen area. These systematic errors are due to a combination of factors including: the limited spatial resolution of the CT scanner; the angle of orientation of the airway within the CT slice; the ability of the scanner to detect edges (the point-spread function); the reconstruction algorithm used; the analysis technique used; and inability to visualise the folding of the epithelium. NAKANO et al. [19] have shown that the half-max method results in very large fractional errors in the measurements of small bronchi. For this reason, techniques such as the maximum likelihood method [20] and score-guided erosion [17] have been developed.
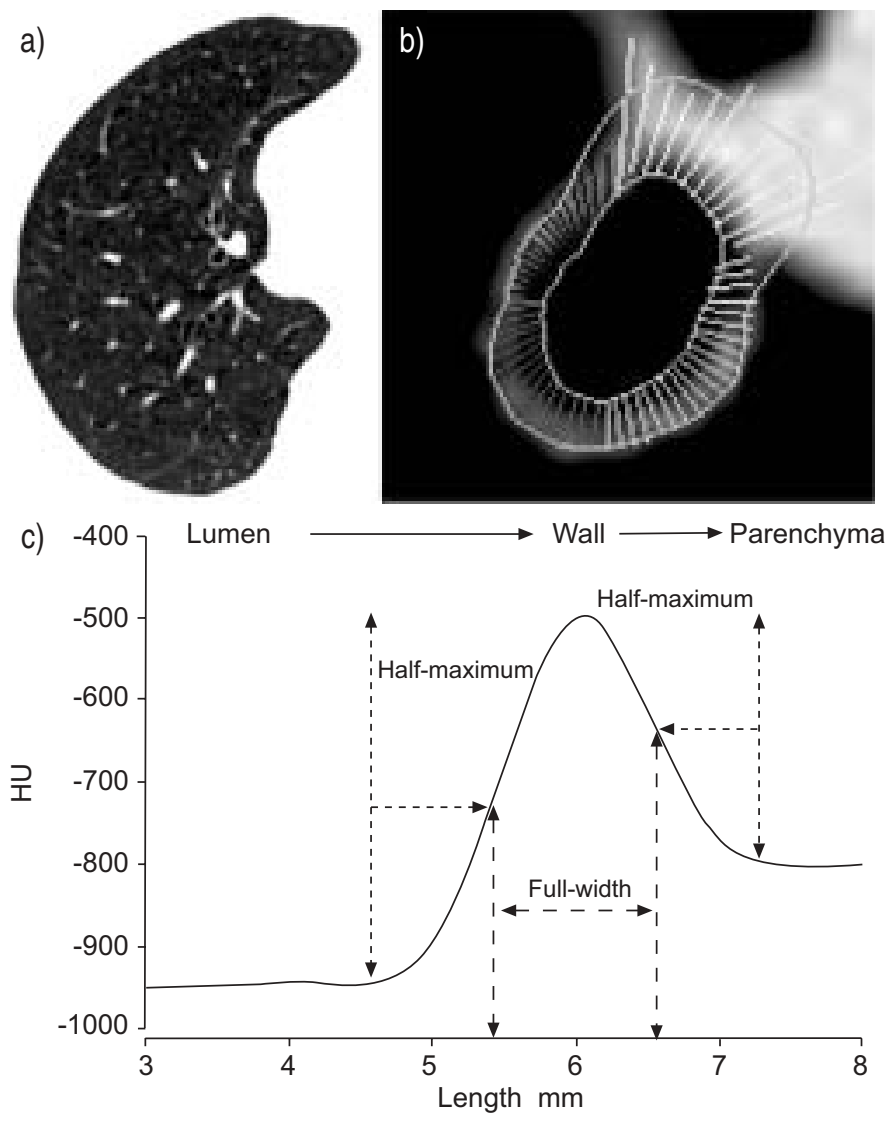

FIGURE 2. c) Airway wall measurement using the full-width at half-maximum algorithm. A representative x-ray attenuation curve for a ray that passes from the lumen through the airway wall and into the parenchyma is shown. The thickness of the wall is determined using the half-maximum point of the change in $x$-ray attenuation as the ray enters and exits the wall. A representative computed tomography image (a) and a magnified view of an airway (b) are shown. The rays can be seen to start at the lumen boundary of the wall and extend to the outer edge. Of note, some rays extend into the pulmonary artery because the artery has similar $x$-ray attenuation values as the airway wall. Those rays are manually deleted and the outer airway border is estimated from the remaining rays using a mathematical spline function. HU: Hounsfield unit.
The errors due to volume averaging are particularly important when airways are sectioned tangentially, as is the case with the majority of airways. KING et al. [17] attempted to compensate for the obliquity of the section, by defining the angle of deviation of each airway from the perpendicular using the centroid of the same airway on the two sections on each side of the section on which the measurements are made. SABA et al. [21] have developed an alternate technique for measuring airways that are not cut in cross-section. This method involves fitting an ellipse to the airway lumen and wall, and shows great promise in correcting the errors in measurement of obliquely cut airways. These techniques claim to be more accurate than the more commonly used techniques, but have not been generally applied, presumably because of the limited availability of the complex algorithms involved.

\section{Quantitative assessment of smaller airways}

In many airway diseases, the important site of airflow obstruction is the small airways [22-24]. It has been reported that airway lumens as small as a $0.5-\mathrm{mm}$ diameter can be measured using CT [25], but, as mentioned previously, there are large errors associated with the measurements of airways this small when the data are obtained using routine clinical scanning parameters [19]. However, NAKANO et al. [26] compared airway measurements from CT scans and histological examination of excised lungs from smokers who had various degrees of airway obstruction. They compared the wall area of small airways (1.27-mm diameter) measured histologically with the wall area percentage of larger airways with a mean internal diameter of $\sim 3.2 \mathrm{~mm}$, and showed that there was a significant association $\left(R^{2}=0.57 ; p=0.001\right)$ between the dimensions of the small and larger airways. These data suggest that, at least for COPD, measuring airway dimensions in the larger bronchi, which are more accurately assessed by CT, can provide an estimate of small airway remodelling. It is likely that the same pathophysiological process that causes small airway obstruction also takes place in larger airways where it has less functional effect.

Even with the use of automated airway detection, it is only possible to make a limited number of measurements in any individual at any time, and, thus, the issue of heterogeneity in airway dimensions is important both for between- and withinsubject comparisons. KING et al. [27] measured heterogeneity in airway narrowing by comparing the variation within a scan to that between scans. However, this study did not address the issue of heterogeneity in baseline airway dimensions, which is important to estimate before the quantitative assessment of airway dimensions is established as an outcome measure in clinical studies. MATSUOKA et al. [28] measured airway wall dimensions from central to peripheral airways, using contiguous 2-mm sections obtained with a MDCT scanner in normal subjects. They reported the variation in various measures of airway lumen and wall dimensions within an individual scan, and as a function of distance from the hilum to the periphery. These data will prove valuable for assessing whether an observed difference or change is real or simply within the variation of the measurement [28].

Another approach for studying airways that are too small to visualise using $\mathrm{CT}$ is to perform expiratory scans, and assess the extent and degree of gas trapping (fig. 3). Heterogeneity of 


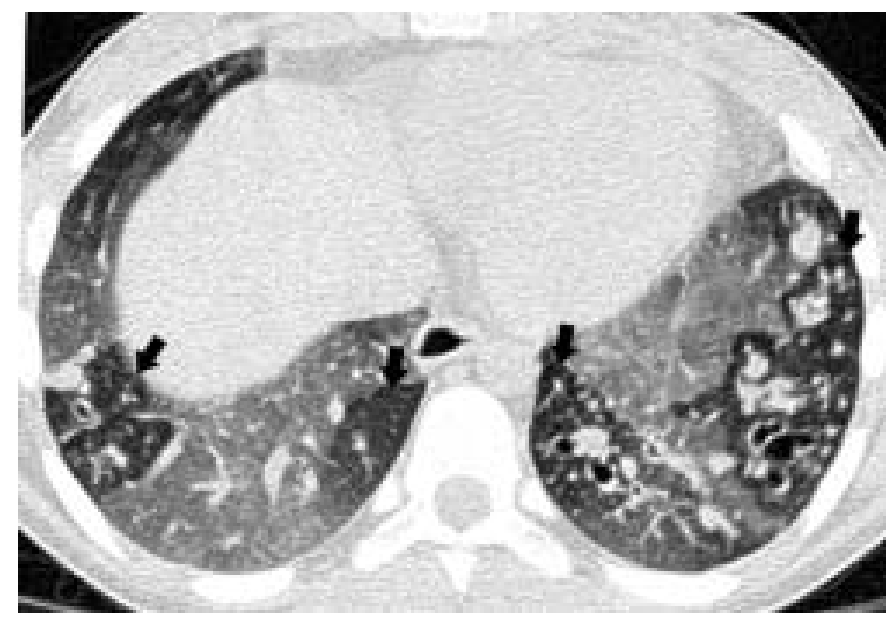

FIGURE 3. An expiratory high-resolution computed tomography scan of the lung base in a cystic fibrosis patient demonstrates bilateral areas of air trapping (arrows).

airway narrowing in disease causes variation in the regional lung volume at which airways close, and this, in turn, leads to heterogeneity in lung density on scans taken at end expiration [29-34]. A limitation of the use of expiratory CT scans is the difficulty in breath-holding at low lung volume. Consistency of expiratory scans may be aided by spirometric gating, but further research is needed to prove the value of these techniques in studying small airway disease.

Heterogeneity of lung attenuation is also present on inspiratory scans where it is attributed to mosaic perfusion. Decreased ventilation to areas of the lung with small airway obstruction results in decreased vascularity and CT attenuation. Bloodflow redistribution to normal lung results in areas of increased vascularity and CT attenuation. This combination of areas of decreased and increased attenuation and perfusion is known as mosaic perfusion. Regional variation in lung perfusion may be an indirect indicator of airway disease, since units with narrowed airways will receive less ventilation and, thus, will have low regional alveolar oxygen tension and hypoxic vasoconstriction.

\section{Qualitative assessment of airways}

A number of CT scoring systems have been developed that allow an assessment of the extent and distribution of airway abnormalities. These scoring systems have been applied in several diseases [35-45]. Scoring systems rely on the subjective detection and grading of direct and indirect signs of airway disease, such as airway wall thickening, bronchiectasis, mosaic perfusion and/or gas trapping [46-50]. However, qualitative studies are sensitive to the display settings (window width and level) of the images, are prone to inter- and intra-reader variability, and are time consuming and, therefore, expensive. While there is reasonably good inter-observer agreement for the diagnosis of bronchiectasis and gas trapping [50], subjective analysis is of very limited value in the assessment of airway wall thickening. It is possible that MDCT scanning can improve the between-observer agreement for bronchiectasis compared with traditional HRCT because of the contiguous slices, as suggested by a study using helical CT [51], but it is unlikely to improve the subjective analysis of airway wall thickness.

\section{CT imaging protocols and safety}

Radiation exposure is an important issue for any studies in which repeat CT scans are planned, as may be the case for CT imaging of airways. Estimates of risk for radiation-induced cancer show that infants and young children are much more susceptible than older children who are, in turn, more susceptible than adults [52-59]. Therefore, most airway research has been restricted to older adults (aged $>55 \mathrm{yrs}$ ) where the risk is very low [52], or children with CF who have a decreased life expectancy [25, 36, 37, 60]. CT scanning of patients who have chronic lung disease and/or control subjects carries a small risk. In research studies, the potential benefit for patients with the disease and/or for the general population should outweigh this risk. In addition, patients and/or healthy control subjects must be informed of the radiation risks and potential benefits of participating in the study.

\section{AIRWAY IMAGING IN ASTHMA Airway dimensions}

Asthma is characterised by chronic airway inflammation, airway remodelling and wall thickening, and reversible airflow obstruction due, in part, to airway smooth muscle contraction [61, 62]. CT scans of asthmatic patients have shown both decreased and increased bronchial lumen area, excessive airway narrowing in response to a variety of stimuli and airway wall thickening, in addition to mosaic perfusion and gas trapping on expiration [63-68]. LYNCH et al. [65] found that $77 \%$ of asthmatic patients and $153(36 \%)$ of 429 bronchi assessed in asthmatic patients had an internal bronchial diameter to pulmonary artery diameter ratio $>1$. Of note, none of the patients had a bronchoarterial diameter ratio $>1.5$. As highlighted by $\mathrm{LYNCH}$ et al. [65], bronchial dilatation in asthmatic patients may partially reflect a reduction in pulmonary artery diameter, due to changes in blood volume or local hypoxia, or may be physiological; caution is advised in diagnosing mild bronchiectasis in this patient population. The detection of mild bronchiectasis can be a problem, especially when there are other reasons for a change in arterial or airway lumen, such as that which occurs at high altitude (i.e. hypoxic vasoconstriction) [69].

A number of investigators have compared airway lumen area in normal and asthmatic subjects. BEIGELMAN-AUBRY et al. [70] demonstrated a lower baseline airway lumen area in asthmatics compared with controls pre-bronchodilator, but the difference was abolished after salbutamol. In addition, the airway lumen diameter to arterial diameter ratio has been reported to be lower in asthmatic patients with a forced expiratory volume in one second (FEV1) $<60 \%$ (mean \pm SD $0.48 \pm 0.11)$ compared with control subjects $(0.65 \pm 0.16)$ and asthmatics who had normal or slightly decreased FEV1 values $(0.60 \pm 0.16$ and $0.60 \pm 0.18$, respectively) [71]. Conversely, NiIMI et al. [72] found no decrease in lumen area in the right apical upper lobe bronchus in asthmatics, irrespective of disease severity, compared with a normal group.

OKAZAWA et al. [73] used CT scans to quantify the degree of airway narrowing produced by inhaled methacholine in normal and asthmatic subjects. They were able to clearly identify airway narrowing of intermediate-sized airways (fig. 4). There was no difference in the pattern of airway narrowing (i.e. large versus small airways) in the asthmatics as opposed to the normal 


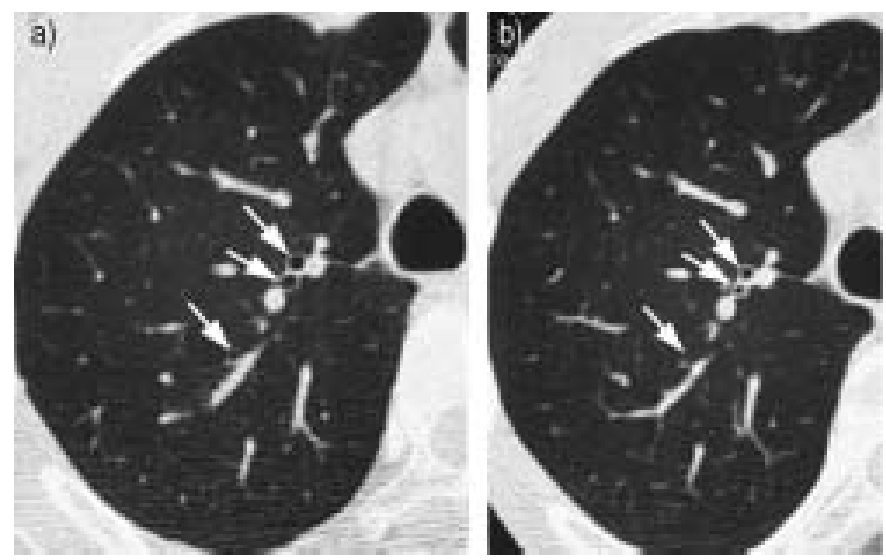

FIGURE 4. Views of the right upper lobe from a high-resolution computed tomography scan in an asthmatic patient before (a) and after (b) methacholine challenge. The decrease in bronchial diameter (arrows) after the inhalation of a dose of methacholine that caused a $\sim 20 \%$ decrease in forced expiratory volume in one second can be clearly seen.

subjects, although, as expected, the same degree of narrowing was achieved using a much lower dose of methacholine in the asthmatics [73]. The frequency distribution of airway luminal area was shifted slightly towards smaller airway lumens in the asthmatics, and the airway walls were significantly thickened compared with normal subjects.

BROWN et al. [74] measured airway narrowing with increasing concentrations of inhaled methacholine in normal subjects who were prevented from taking a deep inspiration after the methacholine inhalation. They demonstrated airway luminal narrowing and no predilection for greater narrowing in any airway size that could be assessed. GoLDIN et al. [75] reported greater decreases in FEV1 and in airway lumen area in small airways after inhalation of methacholine in asthmatic as opposed to normal subjects. KING et al. [27] have recently shown that airway narrowing is heterogeneous in the large airways of asthmatics, and that this heterogeneity is larger than in control subjects.

BROWN et al. [76] measured airway dilation caused by a deep inspiration in asthmatics and normal subjects. It was found that deep inspiration dilated the airways to a comparable degree at baseline, but, after inhaling methacholine, deep inspiration caused further bronchial narrowing in asthmatics as opposed to substantial bronchodilatation in normal subjects. It was suggested that the inadequate bronchodilation in asthmatics following deep inspiration was due to an abnormality in the asthmatic subjects' smooth muscle response to stretch.

All relevant studies of adults and children [14, 34, 66, 72, 7779] show that airway wall thickness is increased in asthmatic subjects, even when the asthma is mild. The degree of wall thickening is related to the duration and severity of asthma, and to the level of airway obstruction [66, 72, 77, 79]. NiIMI et al. [72] showed progressive thickening of the wall of the right apical segmental bronchus in asthmatics as a function of disease severity (baseline FEV1), but, surprisingly, there was no difference in the luminal area of this airway in the severe asthmatics compared with the control subjects or mild asthmatics. Interestingly, for a given degree of airflow obstruction, the airway wall of the right apical bronchus is substantially thicker in asthmatics compared with COPD patients [18, 72].

The relationship between airway wall thickness and airway responsiveness is interesting. Since airway hyperresponsiveness is thought to be a marker of asthma severity, it might be expected that hyperresponsiveness and wall thickness would be positively correlated. Computational modelling studies suggest that thickening of the adventitia, lamina propria and/or smooth muscle layers can all contribute towards an excessive response to contractile agonists. Indeed, BOULET et al. [80] found that individuals who had thicker airways were more responsive. In contrast, LITTLE et al. [66] did not find a relationship between airway wall thickness and airway hyperresponsiveness, which was confirmed in a recent study by NIIMI et al. [81] who found that the dose of methacholine required to increase respiratory resistance was not related to airway wall thickness in asthma. In fact, these authors reported that the slope of the methacholine dose-response curve was inversely related to airway wall thickness. A possible explanation of this finding could be that, at least in some subjects, the process that thickens the airways makes them stiffer and, therefore, less responsive to stimuli such as methacholine [82].

NiIMI et al. [10] have reported that the thickness of the right apical segmental bronchus, adjusted for body surface area, increases as a function of the duration of diagnosed asthma. They also found that $800 \mu \mathrm{g}$ of inhaled beclomethasone q.d. for 12 weeks resulted in a significant decrease in the thickness of the right apical segmental bronchus, although the decrease did not return the airway dimensions to those of an age-matched asymptomatic control group [10].

\section{Gas trapping}

Decreased lung attenuation can be seen on inspiratory scans, but is more apparent on expiratory scans [83]. In asthmatics, low-attenuation areas (LAAs) on inspiratory CT have been reported [65, 84] and are most probably the result of pulmonary blood-flow redistribution secondary to local hypoxic pulmonary vasoconstriction caused by bronchiolar obstruction [63, 85].

On expiratory scans, regional differences in airway closure and/or emptying rate can markedly enhance the heterogeneity of lung attenuation. Although such "gas trapping" is apparent even in asymptomatic individuals who have normal lung function [86], it is markedly increased in patients with asthma and the degree of gas trapping is related to abnormalities of lung function [33, 34, 48, 70, 87].

Mitsunobu et al. [32] showed that mean lung density on inspiratory scans decreased during exacerbations of asthma. GOLDIN et al. [75] showed that the distributions of attenuation values are shifted to the left (low density) during airway narrowing in CT scans acquired before and after methacholine challenge. In a double-blind, randomised, parallel-group pilot study, GolDIN et al. [88] studied the relative efficacy of an extra-fine beclomethasone dipropionate inhaler (hydrofluoroalkane-beclomethasone dipropionate (HFA-BDP); median aerodynamic diameter of $0.8-1.2 \mu \mathrm{m}$ ) and a con- 
ventional chlorofluorocarbon preparation (CFC-BDP; median aerodynamic diameter of $3.5-4.0 \mu \mathrm{m}$ ) in a group of 31 steroid-naive patients with mild-to-moderate asthma. CT was used to assess the relative efficacy of HFA-BDP and CFC-BDP on regional gas trapping. Pre-treatment CT was performed at residual volume before and after methacholine challenge. After 4 weeks of treatment, imaging was repeated before and after the same concentration of methacholine that was administered before the treatment. The quantitative analysis showed that the HFA-BDP group had a significant decrease in baseline gas trapping, and, after inhaled methacholine, they had less increase in gas trapping than subjects treated with CFC-BDP. No significant difference was demonstrated between the two treatment groups with respect to improvement in symptoms, spirometry or methacholine responsiveness. It was concluded that HFA-BDP showed greater efficacy to treat the peripheral airways in asthma, and that this effect is better assessed with functional imaging CT techniques than with conventional physiological tests.

An additional method of analysis, which reflects the heterogeneity of expansion of lung parenchyma, is accomplished by plotting the frequency versus the size of contiguous LAAs. The slope of this relationship has been shown to discriminate between severe and mild/moderate asthmatics, and between asthmatics who smoke versus nonsmokers [89].

\section{Future directions}

CT analysis of airway dimensions in asthma provides additional data to that derived from traditional measures of lung function. Although much work remains to be done in terms of standardising the approach to image acquisition and analysis, there is some evidence that CT may be a more sensitive end-point in clinical trials. As important questions remain to be answered for this common disease, the use of CT in research settings seems justified. The relationship between airway hyperresponsiveness and airway wall dimension (as assessed by (T) is confusing and is a topic that requires more study, as does the contribution of airway wall dimensions to the wide variation in airway responsiveness that can be demonstrated in normal individuals. More studies are needed that relate the degree of airway remodelling (as measured by histology) to the degree of airway wall thickening (as measured by CT) in subjects with asthma and COPD. VIGNOLA et al. [90] recently reported a significant relationship between sputum elastase and the ratio of matrix metalloproteinase-9 to the tissue inhibitor of metalloproteinase- 1 and airway wall thickening in patients who have asthma and COPD. The relationships between CT airway dimensions and biomarkers of inflammation and repair in blood, bronchoalveolar lavage and exhaled breath condensate are important areas for further, future investigations.

\section{AIRWAY IMAGING IN COPD}

COPD occurs predominantly in smokers and is defined by abnormalities of expiratory flow [91]. Decreased expiratory flow in COPD is related to a combination of loss of lung elastic recoil and small airway obstruction. The pathological lesion that is best correlated with loss of lung recoil is emphysema, and CT scanning has been used extensively to detect and quantify emphysema [92-94]. Quantification of the airway lesions by CT has received less attention, but improvements in CT technology now make it possible to detect and quantify the airway abnormalities in these patients. The process that causes the small airway obstruction in COPD is inflammatory in nature and characterised by thickening of all the layers of the bronchiolar walls, as well as an accumulation of mucus in the airway lumen [23]. NAKANO et al. [18] measured lung attenuation and the dimensions of the right upper lobe apical segmental bronchus in 114 smokers, using the half-max method. Ninety-four of the smokers were obstructed (FEV1 $37 \pm 15 \%$ predicted), whereas 20 were unobstructed (mean FEV1 $100 \pm 13 \%$ pred), despite having a comparable smoking history. NAKANO et al. [18] chose the apical segmental bronchus to measure because it is usually cut in cross-section and can be reliably identified on $\mathrm{CT}$, thereby allowing comparison between individuals. They found that the percentage of lung LAA and changes in airway dimensions (wall thickness and percentage of wall area) independently correlated with measures of airflow obstruction. The percentage of wall area was related to FEV1 \% pred, forced vital capacity (FVC) \% pred and residual volume (RV)/total lung capacity (TLC), but not to lung diffusing capacity, while the percentage of LAA was related to FEV1 \% and FEV1/FVC, as well as diffusing capacity. Interestingly, the increase in the percentage of wall area was related both to an increase in wall area and a decrease in lumen area, which contrasts with patients who have asthma, in whom the increased percentage of wall area in the same bronchus was related only to an increase in wall area with a preserved lumen area [72]. Some of the obstructed smokers had only an increase in percentage of wall area, whereas others had only an increased percentage of LAA, and some had both an increase in percentages of wall area and LAA. These data suggest that individual COPD patients may have emphysema or airway wall remodelling as their predominant phenotype, and that these phenotypes can be separated by use of CT scanning. CoxsON et al. [95] measured all cross-sectioned airways and reported a similar result in a large group of obstructed index patients and their smoking siblings, and, in addition, observed that the airway and parenchymal phenotypes showed familial concordance, suggesting that the susceptibility to develop emphysema or airway disease is heritable. Recently, ORLANDI et al. [96] found that patients with COPD who have chronic bronchitis have increased airway wall thickening in comparison with more severely obstructed patients without chronic bronchitis. Conversely, COPD patients without chronic bronchitis had a more significant decrease in lung attenuation. It was suggested that COPD patients with chronic bronchitis have more severe airway remodelling, whereas those without chronic bronchitis have more severe emphysema.

The fact that the airway dimensions of a segmental bronchus relate to measures of airflow obstruction is surprising, since it has long been recognised that the major site of airway narrowing in COPD is membranous airways with an internal diameter $<2 \mathrm{~mm}$. The recent study by NAKANO et al. [26] may explain this result; it was found that the wall area per cent in larger airways, which are clearly identified and accurately measured by CT, was significantly related to the wall area in the bronchioles of the same patients measured histologically. This result supports the observation of TIDDENS et al. [97], who found 
that cartilaginous airway wall thickening was related to airflow obstruction and to small airway inflammation, and suggests that a similar process affects both large and small airways in susceptible COPD patients. Thickening and narrowing of the larger airways, which are amenable to CT assessment, may serve as a surrogate measure to quantify the small airway inflammatory process. The ability to separate airwaypredominant from parenchymal-predominant pathology in COPD may prove useful in applying specific therapies designed to prevent or ameliorate the airway remodelling or parenchymal destruction. In fact, it is conceivable that specific therapy directed at one of these processes could be contraindicated in individuals in whom the other process was predominant.

\section{Future directions}

Future studies in COPD will benefit from the use of spirometric gating and volumetric image acquisition. Threedimensional reconstruction and correction for angled airways will enable investigators to make accurate comparisons of the same airways both within and between subjects. Intervention studies designed to measure changes in the airways and parenchyma, as assessed by $\mathrm{CT}$, are now possible and may provide important insights in this increasingly prevalent disease. Although there are some data on the CT appearance of airway changes during exacerbations of bronchiectasis [98] and CF [99, 100], such knowledge is largely lacking in asthma and COPD, and this represents an important topic of future investigation in human and/or animal models. Another fruitful area for future studies is a determination of the minimal number of CT images that are required to adequately assess airway dimensions in COPD.

\section{AIRWAY IMAGING IN CYSTIC FIBROSIS}

Airway disease in CF is characterised by mucus plugging, chronic infection and an excessive inflammatory response, leading to peripheral airway changes in the first few months of life [101-119]. The characteristic airway abnormalities are bronchiectasis, thickening of the airway wall and mucus plugging $[97,103,107,120-126]$, as shown in figure 5 .

\section{Qualitative studies}

Qualitative CT studies have been performed since 1989, and HRCT airway scoring systems are the most frequently used methods to assess airway abnormalities in CF [35, 37, 59, 60, 99, $100,102,105,127-153]$. All of the systems consist of a composite score for subjective estimates of a number of features on CT scans, which include bronchiectasis, airway wall thickening, mucus plugging, etc. DE JONG et al. [37] compared the reproducibility of the Bhalla score and four modified scoring systems, and showed that all scoring systems were reproducible between and within observers with most interclass r-values $>0.8$. The between- and within-observer variability of scoring the individual components is less well documented. BRODY [128] has shown that the agreement between observers for bronchiectasis, mucus plugging and air trapping is $74 \%, 89 \%$ and $61 \%$, respectively, and DE JONG et al. [37] reported $\kappa$-values ranging $0.40-0.61$ for most features.

In several studies in which the relationship between lung structure and function has been measured, a strong correlation between measures of forced expiratory flow and HRCT scoring systems has been reported [37, 99, 138, 146, 147], except in
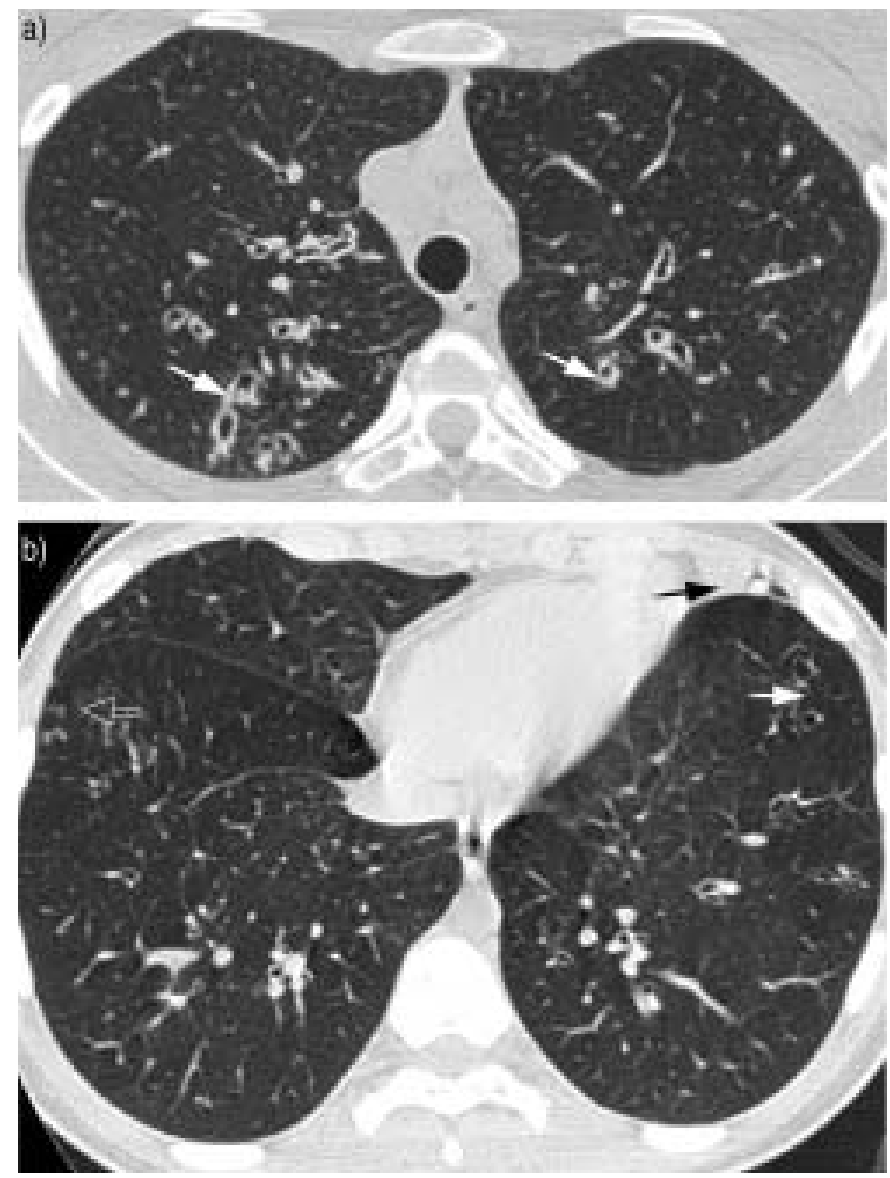

FIGURE 5. a, b) Extensive airway abnormalities evident on computed tomography (CT) in a child with cystic fibrosis (CF) with normal lung function. The CF patient was a 15-yr-old Caucasian female with forced expiratory volume in one second (FEV1) 93\% predicted, forced vital capacity (FVC) 110\% pred, forced mid-expiratory flow $81 \%$ pred and FEV $1 / F V C$ 76\%. The CT images show bronchiectasis with either thick or thin walls (white arrow), atelectasis with an air bronchogram in the lingula (black arrow) and peripheral mucus plugging (open arrow). Mosaic perfusion is also present in both upper and lower lobes.

studies of very young children [128, 134, 143]. The results of two longitudinal studies have suggested that HRCT scoring may be more sensitive than lung function in detecting disease progression in $\mathrm{CF}$; in both studies, pulmonary function tests (PFTs) remained stable over 2 yrs, whereas the HRCT score detected worsening of disease [36, 130]. This is not an unexpected result, since HRCT can detect regional abnormalities such as small areas of atelectasis and bronchiectasis that may be functionally silent. A few, small clinical trials have been performed using HRCT score as an end-point, some of which failed to demonstrate a significant treatment effect; however, the time period between repeat scans was short [132, $137,140,153,154]$.

\section{Quantitative studies}

To date, there have been no studies in which quantitative CT estimates of airway disease have been compared with pathological measures in CF patients. Quantitative assessments of airway dimensions have shown that there is an increase in airway wall thickness and lumen area (bronchiectasis) in CF 
infants and children compared with controls. In CF infants, the dilatation of airway lumen (severity of bronchiectasis) increased significantly with age [25]. In a cross-sectional study, DE JONG et al. [37] did not find a correlation between quantitative measures of airway dimensions and PFTs. In a longitudinal study in which CT scans and PFTs were obtained at baseline and after an interval of 2 yrs, airway wall thickness increased without an increase in lumen area; there was a correlation between the increase in airway wall thickness and decrease in forced midexpiratory flow (FEF25-75) \% pred [60]. Gas trapping is thought to be an early marker of airway disease in CF [150]. In two studies, the severity of gas trapping was evaluated by comparing distribution curves of the HU of individual pixels from inspiratory CT scans with curves from expiratory CT scans $[30,155]$. This measure of air trapping discriminated between CF patients and control subjects, and correlated significantly with RV/TLC and FEF25-75\% pred [30, 155].

\section{Future directions}

The majority of HRCT studies in CF have been carried out using semi-quantitative scoring systems. Aside from the inherent intra- and inter-observer variation, the major limitation of these scoring systems is the lack of consensus on which system to use and the failure to use definitions of CT abnormalities consistently. Quantitative studies of airway dimensions in children are challenging as a result of changes in airway size due to lung growth and the inability to identify airways on subsequent scans due to mucus plugging, or lack of a comparable CT section. In addition, there are real concerns about the risks associated with radiation. With the increasing life expectancy of CF patients, it is possible that these risks will outweigh the potential benefit afforded by early diagnosis.

Despite these concerns, there is accumulating evidence that CT can detect structural damage to the airways in infants and children who are too young to have conventional PFTs and/or when lung function is normal. It is also possible that these early changes are reversible and, therefore, should be treated before structural damage causes irreversible functional deficits. There is increasing evidence that early and aggressive therapy is improving quality of life and longevity in CF [102, 156-160], and, thus, a reasonable case can be made for regular routine CT scans to detect the earliest indication of airway disease. Ultimately, only a randomised clinical trial will answer the question of whether routine CT scanning is warranted in children with CF. To facilitate such studies, a robust quantitative technique to measure airway disease needs to be developed to use with, or in place of, the established CT scoring systems. In the search for early biomarkers of disease progression, it will be useful to compare CT with other noninvasive measures of pulmonary dysfunction, such as helium and sulphur hexafluoride washout ventilation curves [161, 162], or positron emission tomography measures of the intensity of lung inflammation [163]. Finally, more investigation is needed into the radiation hazard associated with different $\mathrm{CT}$ scan protocols to allow development of a protocol that produces the most beneficial information with the lowest risk to the subject.

\section{OTHER IMAGING TECHNIQUES TO EVALUATE AIRWAYS}

A number of novel techniques have been developed to image airways and/or the consequences of airway narrowing without the risk associated with ionising radiation Endobronchial ultrasound is accomplished by introducing an ultrasonic probe into the airways via a fibreoptic bronchoscope, and this technique offers the advantage that the thickness of the different airway wall layers can be measured [164]. In one case study of an asthmatic subject, reversal of central airway oedema was demonstrated following anti-inflammatory therapy [165].

The advent of hyperpolarised gas magnetic resonance imaging (MRI) techniques has opened up whole new avenues of research into ventilation of the lung [166] and the measurement of airway dimensions. Using this technique, threedimensional reconstruction of the airway lumen can be performed to the seventh generation of airways [167]. However, airway wall thickness cannot be quantified, and the limited availability of a hyperpolarised helium or xenon129 source makes the widespread use of this method problematic [167]. It is likely that hyperpolarised gas MRI will remain a limited research tool for the immediate future.

\section{CONCLUSION}

Computed tomography scanning is poised to make a major contribution to the understanding of obstructive airway diseases. Improvements in computed tomography scanning techniques, together with faster quantitative algorithms to measure airway wall and lumen areas and to quantify and localise air trapping, are being applied with increased frequency in research efforts to understand the changes in airways that occur in chronic obstructive lung diseases. It is now possible to obtain computed tomography images with isotropic voxels and at standardised volumes, allowing longitudinal study of specific airways in vivo. Quantitative computed tomography has already led to an improved understanding of variations in airway dimensions in normal individuals, and to a better understanding of the airway changes that occur in asthma, chronic obstructive pulmonary disease and cystic fibrosis. With these refinements, quantitative computed tomography is ready for clinical application, initially in the setting of clinical trials, but ultimately in the clinical management of individual patients. Computed tomography imaging of the airways has inherent limitations: the subdivisions of the airway wall cannot be visualised, the pathological process causing changes in the airway wall cannot be appreciated, and airways $<0.5 \mathrm{~mm}$ in lumen diameter cannot be visualised directly. Furthermore, the radiation dose of computed tomography limits its use in longitudinal studies, particularly in infants and children. Nevertheless, computed tomography is the only readily accessible, relatively noninvasive imaging modality that allows airway wall and lumen dimensions to be measured in vivo. With increased awareness of the role that airway remodelling plays in functional deterioration in these diseases, computed tomography will play an increasing role in research and clinical assessment.

\section{REFERENCES}

1 Ferretti GR, Bricault I, Coulomb M. Virtual tools for imaging of the thorax. Eur Respir J 2001; 18: 381-392.

2 Ferretti GR, Vining DJ, Knoplioch J, Coulomb M. Tracheobronchial tree: three-dimensional spiral CT with 
bronchoscopic perspective. J Comput Assist Tomogr 1996; 20: 777-781.

3 Hoffman EA, Reinhardt JM, Sonka M, et al. Characterization of the interstitial lung diseases via density-based and texture-based analysis of computed tomography images of lung structure and function. Acad Radiol 2003; 10: 1104-1118.

4 Wood SA, Zerhouni EA, Hoford JD, Hoffman EA, Mitzner W. Measurement of three-dimensional lung tree structures by using computed tomography. J Appl Physiol 1995; 79: 1687-1697.

5 Remy-Jardin M, Remy J, Gosselin B, Copin MC, Wurtz A, Duhamel A. Sliding thin slab, minimum intensity projection technique in the diagnosis of emphysema: histopathologic-CT correlation. Radiology 1996; 200: 665-671.

6 Brown RH, Mitzner W, Bulut Y, Wagner EM. Effect of lung inflation in vivo on airways with smooth muscle tone or edema. J Appl Physiol 1997; 82: 491-499.

7 Long FR. High-resolution CT of the lungs in infants and young children. J Thorac Imaging 2001; 16: 251-258.

8 Long FR, Castile RG. Technique and clinical applications of full-inflation and end-exhalation controlled-ventilation chest CT in infants and young children. Pediatr Radiol 2001; 31: 413-422.

9 Long FR, Castile RG, Brody AS, et al. Lungs in infants and young children: improved thin-section CT with a noninvasive controlled-ventilation technique - initial experience. Radiology 1999; 212: 588-593.

10 Niimi A, Matsumoto H, Amitani R, et al. Effect of shortterm treatment with inhaled corticosteroid on airway wall thickening in asthma. Am J Med 2004; 116: 725-731.

11 Webb WR, Gamsu G, Wall SD, Cann CE, Proctor E. CT of a bronchial phantom: factors affecting appearance and size measurements. Invest Radiol 1984; 19: 394-398.

12 Seneterre E, Paganin F, Bruel JM, Michel FB, Bousquet J. Measurement of the internal size of bronchi using high resolution computed tomography (HRCT). Eur Respir J 1994; 7: 596-600.

13 McNamara AE, Muller NL, Okazawa M, Arntorp J, Wiggs BR, Pare PD. Airway narrowing in excised canine lung measured by high-resolution computed tomography. J Appl Physiol 1992; 73: 307-316.

14 Okazawa M, Muller NL, McNamara AE, Child S, Verburgt L, Pare PD. Human airway narrowing measured using high resolution computed tomography. Am J Respir Crit Care Med 1996; 154: 1557-1562.

15 Bankier AA, Fleischmann D, Mallek R, et al. Bronchial wall thickness: appropriate window settings for thinsection CT and radiologic-anatomic correlation. Radiology 1996; 199: 831-836.

16 McNitt-Gray MF, Goldin JG, Johnson TD, Tashkin DP, Aberle DR. Development and testing of image-processing methods for the quantitative assessment of airway hyperresponsiveness from high-resolution CT images. J Comput Assist Tomogr 1997; 21: 939-947.

17 King GG, Muller NL, Whittall KP, Xiang QS, Pare PD. An analysis algorithm for measuring airway lumen and wall areas from high-resolution computed tomographic data. Am J Respir Crit Care Med 2000; 161: 574-580.
18 Nakano Y, Muro S, Sakai H, et al. Computed tomographic measurements of airway dimensions and emphysema in smokers. Correlation with lung function. Am J Respir Crit Care Med 2000; 162: 1102-1108.

19 Nakano Y, Whittall KP, Kalloger SE, Coxson HO, Pare PD, English JC. Development and validation of human airway analysis algorithm using multidetector row CT. Proceedings of SPIE 2002; 4683: 460-469.

20 Reinhardt JM, D'Souza ND, Hoffman EA. Accurate measurement of intrathoracic airways. IEEE Trans Med Imaging 1997; 16: 820-827.

21 Saba OI, Hoffman EA, Reinhardt JM. Maximizing quantitative accuracy of lung airway lumen and wall measures obtained from X-ray CT imaging. J Appl Physiol 2003; 95: 1063-1075.

22 Hogg JC, Macklem PT, Thurlbeck WM. Site and nature of airway obstruction in chronic obstructive lung disease. New Engl J Med 1968; 278: 1355-1360.

23 Hogg JC, Chu F, Utokaparch S, et al. The nature of smallairway obstruction in chronic obstructive pulmonary disease. N Engl J Med 2004; 350: 2645-2653.

24 Hogg JC. Pathophysiology of airflow limitation in chronic obstructive pulmonary disease. Lancet 2004; 364: 709-721.

25 Long FR, Williams RS, Castile RG. Structural airway abnormalities in infants and young children with cystic fibrosis. J Pediatr 2004; 144: 154-161.

26 Nakano Y, Wong JC, de Jong PA, et al. The prediction of small airway dimensions using computed tomography. Am J Respir Crit Care Med 2005; 171: 142-146.

27 King GG, Carroll JD, Muller NL, et al. Heterogeneity of narrowing in normal and asthmatic airways measured by HRCT. Eur Respir J 2004; 24: 211-218.

28 Matsuoka S, Kurihara Y, Nakajima Y, Niimi H, Ashida H, Kaneoya K. Serial change in airway lumen and wall thickness at thin-section CT in asymptomatic subjects. Radiology 2005; 234: 595-603.

29 Gevenois PA, De Vuyst P, Sy M, et al. Pulmonary emphysema: quantitative CT during expiration. Radiology 1996; 199: 825-829.

30 Goris ML, Zhu HJ, Blankenberg F, Chan F, Robinson TE. An automated approach to quantitative air trapping measurements in mild cystic fibrosis. Chest 2003; 123: 1655-1663.

31 Mishima M, Hirai $\mathrm{T}$, Itoh $\mathrm{H}$, et al. Complexity of terminal airspace geometry assessed by lung computed tomography in normal subjects and patients with chronic obstructive pulmonary disease. Proc Natl Acad Sci USA 1999; 96: 8829-8834.

32 Mitsunobu F, Ashida K, Hosaki Y, et al. Decreased computed tomographic lung density during exacerbation of asthma. Eur Respir J 2003; 22: 106-112.

33 Newman KB, Lynch DA, Newman LS, Ellegood D, Newell JD Jr. Quantitative computed tomography detects air trapping due to asthma. Chest 1994; 106: 105-109.

34 Gono H, Fujimoto K, Kawakami S, Kubo K. Evaluation of airway wall thickness and air trapping by HRCT in asymptomatic asthma. Eur Respir J 2003; 22: 965-971.

35 Bhalla M, Turcios N, Aponte V, et al. Cystic fibrosis: scoring system with thin-section CT. Radiology 1991; 179: 783-788. 
36 de Jong PA, Nakano Y, Lequin $\mathrm{MH}$, et al. Progressive damage on high resolution computed tomography despite stable lung function in cystic fibrosis. Eur Respir J 2004; 23: 93-97.

37 de Jong PA, Ottink MD, Robben SG, et al. Computed tomography assessment of pulmonary disease in children with cystic fibrosis: various scoring system comparisons and bronchial and arterial measurements. Radiology 2004; 231: 434-439.

38 Drent M, De Vries J, Lenters M, et al. Sarcoidosis: assessment of disease severity using HRCT. Eur Radiol 2003; 13: 2462-2471.

39 Edwards EA, Metcalfe R, Milne DG, Thompson J, Byrnes CA. Retrospective review of children presenting with non cystic fibrosis bronchiectasis: HRCT features and clinical relationships. Pediatr Pulmonol 2003; 36: 87-93.

40 Ikonen T, Kivisaari L, Harjula AL, et al. Value of highresolution computed tomography in routine evaluation of lung transplantation recipients during development of bronchiolitis obliterans syndrome. J Heart Lung Transplant 1996; 15: 587-595.

41 Kazerooni EA, Martinez FJ, Flint A, et al. Thin-section CT obtained at $10-\mathrm{mm}$ increments versus limited three-level thin-section CT for idiopathic pulmonary fibrosis: correlation with pathologic scoring. AJR Am J Roentgenol 1997; 169: 977-983.

42 Kubota J, Ohki Y, Inoue $\mathrm{T}$, et al. Ultrafast CT scoring system for assessing bronchopulmonary dysplasia: reproducibility and clinical correlation. Radiat Med 1998; 16: 167-174.

43 Loubeyre P, Paret M, Revel D, Wiesendanger T, Brune J. Thin-section CT detection of emphysema associated with bronchiectasis and correlation with pulmonary function tests. Chest 1996; 109: 360-365.

44 Manson D, Reid B, Dalal I, Roifman CM. Clinical utility of high-resolution pulmonary computed tomography in children with antibody deficiency disorders. Pediatr Radiol 1997; 27: 794-798.

45 Terasaki H, Fujimoto K, Hayabuchi N, Ogoh Y, Fukuda T, Muller NL. Respiratory symptoms in rheumatoid arthritis: relation between high resolution $\mathrm{CT}$ findings and functional impairment. Radiat Med 2004; 22: 179-185.

46 Phillips MS, Williams MP, Flower CD. How useful is computed tomography in the diagnosis and assessment of bronchiectasis? Clin Radiol 1986; 37: 321-325.

47 Silverman PM, Godwin JD. CT/bronchographic correlations in bronchiectasis. J Comput Assist Tomogr 1987; 11: $52-56$.

48 Grenier PA, Beigelman-Aubry C, Fetita C, Preteux F, Brauner MW, Lenoir S. New frontiers in CT imaging of airway disease. Eur Radiol 2002; 12: 1022-1044.

49 Young K, Aspestrand F, Kolbenstvedt A. High resolution CT and bronchography in the assessment of bronchiectasis. Acta Radiol 1991; 32: 439-441.

50 Diederich S, Jurriaans E, Flower CD. Interobserver variation in the diagnosis of bronchiectasis on high-resolution computed tomography. Eur Radiol 1996; 6: 801-806.

51 Lucidarme O, Grenier P, Coche E, Lenoir S, Aubert B, Beigelman C. Bronchiectasis: comparative assessment with thin-section CT and helical CT. Radiology 1996; 200: 673-679.

52 Mayo JR, Aldrich J, Muller NL. Radiation exposure at chest CT: a statement of the Fleischner Society. Radiology 2003; 228: 15-21.

53 Brenner DJ. Estimating cancer risks from pediatric CT: going from the qualitative to the quantitative. Pediatr Radiol 2002; 32: 228-233.

54 Brenner D, Elliston C, Hall E, Berdon W. Estimated risks of radiation-induced fatal cancer from pediatric CT. AJR Am J Roentgenol 2001; 176: 289-296.

55 Pierce DA, Preston DL. Risks from low doses of radiation. Science 1996; 272: 632-633.

56 Pierce DA, Shimizu Y, Preston DL, Vaeth M, Mabuchi K. Studies of the mortality of atomic bomb survivors. Report 12, Part I. Cancer: 1950-1990. Radiat Res 1996; 146: 1-27.

57 Preston DL, Kato H, Kopecky K, Fujita S. Studies of the mortality of A-bomb survivors. 8. Cancer mortality, 19501982. Radiat Res 1987; 111: 151-178.

58 Preston DL, Shimizu Y, Pierce DA, Suyama A, Mabuchi K. Studies of mortality of atomic bomb survivors. Report 13: Solid cancer and noncancer disease mortality: 1950-1997. Radiat Res 2003; 160: 381-407.

59 Brody AS. Thoracic CT technique in children. J Thorac Imaging 2001; 16: 259-268.

60 de Jong PA, Nakano Y, Hop WC, et al. Changes in airway dimensions on computed tomography scans of children with cystic fibrosis. Am J Respir Crit Care Med 2005; (In press).

61 Kuwano K, Bosken CH, Pare PD, Bai TR, Wiggs BR, Hogg JC. Small airways dimensions in asthma and in chronic obstructive pulmonary disease. Am Rev Respir Dis 1993; 148: 1220-1225.

62 Bai TR. Abnormalities in airway smooth muscle in fatal asthma. Am Rev Respir Dis 1990; 141: 552-557.

63 Silva CI, Colby TV, Muller NL. Asthma and associated conditions: high-resolution $\mathrm{CT}$ and pathologic findings. AJR Am J Roentgenol 2004; 183: 817-824.

64 Paganin F, Seneterre E, Chanez P, et al. Computed tomography of the lungs in asthma: influence of disease severity and etiology. Am J Respir Crit Care Med 1996; 153 : 110-114.

65 Lynch DA, Newell JD, Tschomper BA, Cink TM, Newman LS, Bethel R. Uncomplicated asthma in adults: comparison of CT appearance of the lungs in asthmatic and healthy subjects. Radiology 1993; 188: 829-833.

66 Little SA, Sproule MW, Cowan MD, et al. High resolution computed tomographic assessment of airway wall thickness in chronic asthma: reproducibility and relationship with lung function and severity. Thorax 2002; 57: 247-253.

67 Paganin F, Trussard V, Seneterre E, et al. Chest radiography and high resolution computed tomography of the lungs in asthma. Am Rev Respir Dis 1992; 146: 1084-1087.

68 Kinsella M, Muller NL, Staples C, Vedal S, ChanYeung M. Hyperinflation in asthma and emphysema. Assessment by pulmonary function testing and computed tomography. Chest 1988; 94: 286-289.

69 Kim JS, Muller NL, Park CS, et al. Bronchoarterial ratio on thin section CT: comparison between high altitude and sea level. J Comput Assist Tomogr 1997; 21: 306-311. 
70 Beigelman-Aubry C, Capderou A, Grenier PA, et al. Mild intermittent asthma: CT assessment of bronchial crosssectional area and lung attenuation at controlled lung volume. Radiology 2002; 223: 181-187.

71 Park CS, Muller NL, Worthy SA, Kim JS, Awadh N, Fitzgerald M. Airway obstruction in asthmatic and healthy individuals: inspiratory and expiratory thinsection CT findings. Radiology 1997; 203: 361-367.

72 Niimi A, Matsumoto H, Amitani R, et al. Airway wall thickness in asthma assessed by computed tomography. Relation to clinical indices. Am J Respir Crit Care Med 2000; 162: 1518-1523.

73 Okazawa M, Muller N, McNamara AE, Child S, Verburgt L, Pare PD. Human airway narrowing measured using high resolution computed tomography. Am J Respir Crit Care Med 1996; 154: 1557-1562.

74 Brown RH, Croisille P, Mudge B, Diemer FB, Permutt S, Togias A. Airway narrowing in healthy humans inhaling methacholine without deep inspirations demonstrated by HRCT. Am J Respir Crit Care Med 2000; 161: 1256-1263.

75 Goldin JG, McNitt-Gray MF, Sorenson SM, et al. Airway hyperreactivity: assessment with helical thin-section CT. Radiology 1998; 208: 321-329.

76 Brown RH, Scichilone N, Mudge B, Diemer FB, Permutt S, Togias A. High-resolution computed tomographic evaluation of airway distensibility and the effects of lung inflation on airway caliber in healthy subjects and individuals with asthma. Am J Respir Crit Care Med 2001; 163: 994-1001.

77 Awadh N, Muller NL, Park CS, Abboud RT, FitzGerald JM. Airway wall thickness in patients with near fatal asthma with or without fixed airflow obstruction. Thorax 1998; 53: 248-253.

78 Ketai L, Coutsias C, Williamson S, Coutsias V. Thinsection CT evidence of bronchial thickening in children with stable asthma: bronchoconstriction or airway remodeling? Acad Radiol 2001; 8: 257-264.

79 Kasahara K, Shiba K, Ozawa T, Okuda K, Adachi M. Correlation between the bronchial subepithelial layer and whole airway wall thickness in patients with asthma. Thorax 2002; 57: 242-246.

80 Boulet L, Belanger M, Carrier G. Airway responsiveness and bronchial-wall thickness in asthma with or without fixed airflow obstruction. Am J Respir Crit Care Med 1995; 152: 865-871.

81 Niimi A, Matsumoto $H$, Takemura M, Ueda T, Chin K, Mishima M. Relationship of airway wall thickness to airway sensitivity and airway reactivity in asthma. Am J Respir Crit Care Med 2003; 168: 983-988.

82 Brackel HJ, Pedersen OF, Mulder PG, Overbeek SE, Kerrebijn KF, Bogaard JM. Central airways behave more stiffly during forced expiration in patients with asthma. Am J Respir Crit Care Med 2000; 162: 896-904.

83 Park JW, Hong YK, Kim CW, Kim DK, Choe KO, Hong CS. High-resolution computed tomography in patients with bronchial asthma: correlation with clinical features, pulmonary functions and bronchial hyperresponsiveness. J Investig Allergol Clin Immunol 1997; 7: 186-192.

84 Grenier P, Mourey-Gerosa I, Benali K, et al. Abnormalities of the airways and lung parenchyma in asthmatics: CT observations in 50 patients and inter- and intraobserver variability. Eur Radiol 1996; 6: 199-206.
85 Austin JH, Muller NL, Friedman PJ, et al. Glossary of terms for CT of the lungs: recommendations of the Nomenclature Committee of the Fleischner Society. Radiology 1996; 200: 327-331.

86 Tanaka N, Matsumoto T, Miura G, et al. Air trapping at CT: high prevalence in asymptomatic subjects with normal pulmonary function. Radiology 2003; 227: 776-785.

87 Lucidarme O, Coche E, Cluzel P, Mourey-Gerosa I, Howarth N, Grenier P. Expiratory CT scans for chronic airway disease: correlation with pulmonary function test results. AJR Am J Roentgenol 1998; 170: 301-307.

88 Goldin JG, Tashkin DP, Kleerup EC, et al. Comparative effects of hydrofluoroalkane and chlorofluorocarbon beclomethasone dipropionate inhalation on small airways: assessment with functional helical thin-section computed tomography. J Allergy Clin Immunol 1999; 104: S258-S267.

89 Mitsunobu F, Ashida K, Hosaki Y, et al. Complexity of terminal airspace geometry assessed by computed tomography in asthma. Am J Respir Crit Care Med 2003; 167: 411-417.

90 Vignola AM, Paganin F, Capieu L, et al. Airway remodelling assessed by sputum and high-resolution computed tomography in asthma and COPD. Eur Respir J 2004; 24: 910-917.

91 Pauwels RA, Buist AS, Calverley PM, Jenkins CR, Hurd SS, GOLD Scientific Committee. Global strategy for the diagnosis, management, and prevention of chronic obstructive pulmonary disease. NHLBI/WHO Global Initiative for Chronic Obstructive Lung Disease (GOLD) Workshop summary. Am J Respir Crit Care Med 2001; 163: 1256-1276.

92 Müller NL, Staples CA, Miller RR, Abboud RT. "Density mask". An objective method to quantitate emphysema using computed tomography. Chest 1988; 94: 782-787.

93 Hayhurst MD, Flenley DC, McLean A, et al. Diagnosis of pulmonary emphysema by computerized tomography. Lancet 1984; 2: 320-322.

94 Gevenois PA, de Maertelaer V, De Vuyst P, Zanen J, Yernault JC. Comparison of computed density and macroscopic morphometry in pulmonary emphysema. Am J Respir Crit Care Med 1995; 152: 653-657.

95 Coxson HO, Patel BD, Nakano Y, et al. The role of emphysema and airway wall dimensions in chronic obstructive pulmonary disease (COPD). Am J Respir Crit Care Med 2003; 167: A81.

96 Orlandi I, Moroni C, Camiciottoli G, et al. Chronic obstructive pulmonary disease: thin-section CT measurement of airway wall thickness and lung attenuation. Radiology 2005; 234: 604-610.

97 Tiddens HA, Pare PD, Hogg JC, Hop WC, Lambert R, de Jongste JC. Cartilaginous airway dimensions and airflow obstruction in human lungs. Am J Respir Crit Care Med 1995; 152: 260-266.

98 Ooi GC, Khong PL, Chan-Yeung M, et al. High-resolution CT quantification of bronchiectasis: clinical and functional correlation. Radiology 2002; 225: 663-672.

99 Robinson TE, Leung AN, Northway WH, et al. Spirometer-triggered high-resolution computed tomography and pulmonary function measurements during an 
acute exacerbation in patients with cystic fibrosis. J Pediatr 2001; 138: 553-559.

100 Shah RM, Sexauer W, Ostrum BJ, Fiel SB, Friedman AC. High-resolution $\mathrm{CT}$ in the acute exacerbation of cystic fibrosis: evaluation of acute findings, reversibility of those findings, and clinical correlation. AJR Am J Roentgenol 1997; 169: 375-380.

101 Tiddens H, Silverman M, Bush A. The role of inflammation in airway disease: remodeling. Am J Respir Crit Care Med 2000; 162: S7-S10.

102 Tiddens HA. Detecting early structural lung damage in cystic fibrosis. Pediatr Pulmonol 2002; 34: 228-231.

103 Tiddens HA, Koopman LP, Lambert RK, et al. Cartilaginous airway wall dimensions and airway resistance in cystic fibrosis lungs. Eur Respir J 2000; 15: 735-742.

104 Dakin CJ, Numa AH, Wang H, Morton JR, Vertzyas CC, Henry RL. Inflammation, infection, and pulmonary function in infants and young children with cystic fibrosis. Am J Respir Crit Care Med 2002; 165: 904-910.

105 Dakin CJ, Pereira JK, Henry RL, Wang H, Morton JR. Relationship between sputum inflammatory markers, lung function, and lung pathology on high-resolution computed tomography in children with cystic fibrosis. Pediatr Pulmonol 2002; 33: 475-482.

106 Gibson RL, Burns JL, Ramsey BW. Pathophysiology and management of pulmonary infections in cystic fibrosis. Am J Respir Crit Care Med 2003; 168: 918-951.

107 Bedrossian CW, Greenberg SD, Singer DB, Hansen JJ, Rosenberg HS. The lung in cystic fibrosis. A quantitative study including prevalence of pathologic findings among different age groups. Hum Pathol 1976; 7: 195-204.

108 Oppenheimer EH. Similarity of the tracheobronchial mucous glands and epithelium in infants with and without cystic fibrosis. Hum Pathol 1981; 12: 36-48.

109 Mellins RB. The site of airway obstruction in cystic fibrosis. Pediatrics 1969; 44: 315-318.

110 Hamutcu R, Rowland JM, Horn MV, et al. Clinical findings and lung pathology in children with cystic fibrosis. Am J Respir Crit Care Med 2002; 165: 1172-1175.

111 Tomashefski JF Jr, Bruce M, Goldberg HI, Dearborn DG. Regional distribution of macroscopic lung disease in cystic fibrosis. Am Rev Respir Dis 1986; 133: 535-540.

112 Sturgess J, Imrie J. Quantitative evaluation of the development of tracheal submucosal glands in infants with cystic fibrosis and control infants. Am J Pathol 1982; 106: 303-311.

113 Chow CW, Landau LI, Taussig LM. Bronchial mucous glands in the newborn with cystic fibrosis. Eur J Pediatr 1982; 139: 240-243.

114 Tirouvanziam R, Khazaal I, Peault B. Primary inflammation in human cystic fibrosis small airways. Am J Physiol Lung Cell Mol Physiol 2002; 283: L445-L451.

115 Zuelzer WZ, Newton WA. The pathogenesis of fibrocystic disease of the pancreas. Pediatrics 1949; 4: 53-69.

116 Karp CL, Flick LM, Park KW, et al. Defective lipoxinmediated anti-inflammatory activity in the cystic fibrosis airway. Nat Immunol 2004; 5: 388-392.

117 Reid L, de Haller R. The bronchial mucous glands-their hypertrophy and change in intracellular mucus. Bibl Paediatr 1967; 86: 195-199.
118 Ornoy A, Arnon J, Katznelson D, Granat M, Caspi B, Chemke J. Pathological confirmation of cystic fibrosis in the fetus following prenatal diagnosis. Am J Med Genet 1987; 28: 935-947.

119 Wentworth P, Gough J, Wentworth JE. Pulmonary changes and cor pulmonale in mucoviscidosis. Thorax 1968; 23: 582-589.

120 Ogrinc G, Kampalath B, Tomashefski JF Jr. Destruction and loss of bronchial cartilage in cystic fibrosis. Hum Pathol 1998; 29: 65-73.

121 Sobonya RE, Taussig LM. Quantitative aspects of lung pathology in cystic fibrosis. Am Rev Respir Dis 1986; 134: 290-295.

122 Hogg JC, Williams J, Richardson JB, Macklem PT, Thurlbeck WM. Age as a factor in the distribution of lower-airway conductance and in the pathologic anatomy of obstructive lung disease. N Engl J Med 1970; 282: 1283-1287.

123 Reid LM. Reduction in bronchial subdivision in bronchiectasis. Thorax 1950; 5: 233-247.

124 Cosio M, Ghezzo H, Hogg JC, et al. The relations between structural changes in small airways and pulmonaryfunction tests. N Engl J Med 1978; 298: 1277-1281.

125 Dovey M, Wisseman CL, Roggli VL, Roomans GM, Shelburne JD, Spock A. Ultrastructural morphology of the lung in cystic fibrosis. J Submicrosc Cytol Pathol 1989; 21: $521-534$

126 Leigh MW, Kylander JE, Yankaskas JR, Boucher RC. Cell proliferation in bronchial epithelium and submucosal glands of cystic fibrosis patients. Am J Respir Cell Mol Biol 1995; 12: 605-612.

127 Brody AS. Cystic fibrosis: when should high-resolution computed tomography of the chest be obtained? Pediatrics 1998; 101: 1071.

128 Brody AS. Early morphologic changes in the lungs of asymptomatic infants and young children with cystic fibrosis. J Pediatr 2004; 144: 145-146.

129 Brody AS, Klein JS, Molina PL, Campbell JD, Millard SP, Quan J. High-resolution CT correlates with the number of exacerbations in young children with CF. Pediatr Pulmonol 2003; 36: Suppl. 25, A389.

130 Brody AS, Molina PL, Klein JS, Campbell JD, Millard SP, Quan J. High-resolution CT is more sensitive to longitudinal decline in lung status in young children with $\mathrm{CF}$ than pulmonary function tests. Pediatr Pulmonol 2003; 36: Suppl. 25, A388.

131 Brody AS, Molina PL, Klein JS, Rothman BS Ramagopal M, Swartz DR. High-resolution computed tomography of the chest in children with cystic fibrosis: support for use as an outcome surrogate. Pediatr Radiol 1999; 29: 731-735.

132 Brody AS, Robinson TE, Knowles M, Goris ML, LaVange LM, Engles JM. The use of high resolution CT in intervention studies of cystic fibrosis. Pediatr Pulmonol 2004; 38: Suppl. 27, A321.

133 de Jong PA, Nakano Y, Lequin $\mathrm{MH}$, et al. Estimation of lung growth using computed tomography. Eur Respir J 2003; 22: 235-238.

134 Demirkazik FB, Ariyurek OM, Ozcelik U, Gocmen A, Hassanabad HK, Kiper N. High resolution CT in children 
with cystic fibrosis: correlation with pulmonary functions and radiographic scores. Eur J Radiol 2001; 37: 54-59.

135 Maffessanti M, Candusso M, Brizzi F, Piovesana F. Cystic fibrosis in children: HRCT findings and distribution of disease. J Thorac Imaging 1996; 11: 27-38.

136 Marchant JM, Masel JP, Dickinson FL, Masters IB, Chang AB. Application of chest high-resolution computer tomography in young children with cystic fibrosis. Pediatr Pulmonol 2001; 31: 24-29.

137 Nasr SZ, Kuhns LR, Brown RW, Hurwitz ME, Sanders GM, Strouse PJ. Use of computerized tomography and chest $\mathrm{x}$-rays in evaluating efficacy of aerosolized recombinant human DNase in cystic fibrosis patients younger than age 5 years: a preliminary study. Pediatr Pulmonol 2001; 31: 377-382.

138 Nathanson I, Conboy K, Murphy S, Afshani E, Kuhn JP. Ultrafast computerized tomography of the chest in cystic fibrosis: a new scoring system. Pediatr Pulmonol 1991; 11: 81-86.

139 Oikonomou A, Manavis J, Karagianni P, et al. Loss of FEV1 in cystic fibrosis: correlation with HRCT features. Eur Radiol 2002; 12: 2229-2235.

140 Robinson TE, Leung AN, Northway WH, et al. Composite spirometric-computed tomography outcome measure in early cystic fibrosis lung disease. Am J Respir Crit Care Med 2003; 168: 588-593.

141 Santamaria F, Grillo G, Guidi G, et al. Cystic fibrosis: when should high-resolution computed tomography of the chest be obtained? Pediatrics 1998; 101: 908-913.

142 Santis G, Hodson ME, Strickland B. High resolution computed tomography in adult cystic fibrosis patients with mild lung disease. Clin Radiol 1991; 44: 20-22.

143 Stiglbauer R, Schurawitzki H, Eichler I, Vergesslich KA, Gotz M. High resolution CT in children with cystic fibrosis. Acta Radiol 1992; 33: 548-553.

144 Taccone A, Romano L, Marzoli A, Girosi D, Dell'Acqua A, Romano C. High-resolution computed tomography in cystic fibrosis. Eur J Radiol 1992; 15: 125-129.

145 Hansell DM, Strickland B. High-resolution computed tomography in pulmonary cystic fibrosis. Br J Radiol 1989; 62: 1-5.

146 Helbich TH, Heinz-Peer G, Eichler I, et al. Cystic fibrosis: CT assessment of lung involvement in children and adults. Radiology 1999; 213: 537-544.

147 Helbich TH, Heinz-Peer G, Fleischmann D, et al. Evolution of CT findings in patients with cystic fibrosis. AJR Am J Roentgenol 1999; 173: 81-88.

148 Logan PM, O'Laoide RM, Mulherin D, O'Mahony S, FitzGerald MX, Masterson JB. High resolution computed tomography in cystic fibrosis: correlation with pulmonary function and assessment of prognostic value. Ir J Med Sci 1996; 165: 27-31.

149 Donnelly LF, Gelfand MJ, Brody AS, Wilmott RW. Comparison between morphologic changes seen on high-resolution $\mathrm{CT}$ and regional pulmonary perfusion seen on SPECT in patients with cystic fibrosis. Pediatr Radiol 1997; 27: 920-925.

150 Dorlochter L, Nes H, Fluge G, Rosendahl K. High resolution CT in cystic fibrosis: the contribution of expiratory scans. Eur J Radiol 2003; 47: 193-198.
151 Hubert D, Fajac I, Bienvenu T, et al. Diagnosis of cystic fibrosis in adults with diffuse bronchiectasis. J Cyst Fibros 2004; 3: 15-22.

152 Lugo-Olivieri CH, Soyer PA, Fishman EK. Cystic fibrosis: spectrum of thoracic and abdominal CT findings in the adult patient. Clin Imaging 1998; 22: 346-354.

153 Moss RB, Rodman D, Spencer LT, et al. Repeated adenoassociated virus serotype 2 aerosol-mediated cystic fibrosis transmembrane regulator gene transfer to the lungs of patients with cystic fibrosis: a multicenter, double-blind, placebo-controlled trial. Chest 2004; 125: 509-521.

154 Nasr SZ, Gordon D, Yu X, Sakmar E, Eckhardt BP, Strause $\mathrm{P}$. Comparison of high resolution computed tomography (HRCT) and pulmonary function testing in evaluating of the effect of tobramycin for inhalation (TSI) in cystic fibrosis (CF) subjects with mild lung disease. Pediatr Pulmonol 2004; 38: Suppl. 27, A323.

155 Bonnel AS, Song SM, Kesavarju K, et al. Quantitative airtrapping analysis in children with mild cystic fibrosis lung disease. Pediatr Pulmonol 2004; 38: 396-405.

156 Kulich M, Rosenfeld M, Goss CH, Wilmott R. Improved survival among young patients with cystic fibrosis. J Pediatr 2003; 142: 631-636.

157 Quan JM, Tiddens HA, Sy JP, et al. A two-year randomized, placebo-controlled trial of dornase alfa in young patients with cystic fibrosis with mild lung function abnormalities. J Pediatr 2001; 139: 813-820.

158 Doring G, Hoiby N. Early intervention and prevention of lung disease in cystic fibrosis: a European consensus. J Cyst Fibros 2004; 3: 67-91.

159 Schidlow DV. "Maintaining the horizontal line": early intervention and prevention of CF lung disease. J Cyst Fibros 2004; 3: 63-66.

160 Robinson PJ. Dornase alfa in early cystic fibrosis lung disease. Pediatr Pulmonol 2002; 34: 237-241.

161 Aurora P, Gustafsson P, Bush A, et al. Multiple breath inert gas washout as a measure of ventilation distribution in children with cystic fibrosis. Thorax 2004; 59: 1068-1073.

162 Gustafsson PM, Aurora P, Lindblad A. Evaluation of ventilation maldistribution as an early indicator of lung disease in children with cystic fibrosis. Eur Respir J 2003; 22: 972-979.

163 Labiris NR, Nahmias C, Freitag AP, Thompson ML, Dolovich MB. Uptake of 18fluorodeoxyglucose in the cystic fibrosis lung: a measure of lung inflammation? Eur Respir J 2003; 21: 848-854.

164 Shaw TJ, Wakely SL, Peebles CR, et al. Endobronchial ultrasound to assess airway wall thickening: validation in vitro and in vivo. Eur Respir J 2004; 23: 813-817.

165 Yamasaki A, Tomita K, Sano H, et al. Measuring subepithelial thickness using endobronchial ultrasonography in a patient with asthma: a case report. Lung 2003; 181: 115-120.

166 van Beek EJ, Wild JM, Kauczor HU, Schreiber W, Mugler JP 3rd, de Lange EE. Functional MRI of the lung using hyperpolarized 3-helium gas. J Magn Reson Imaging 2004; 20: 540-554.

167 Tooker AC, Hong KS, McKinstry EL, Costello P, Jolesz FA, Albert MS. Distal airways in humans: dynamic hyperpolarized $3 \mathrm{He}$ MR imaging: feasibility. Radiology 2003; 227: 575-579. 